\title{
Apoio à Interação entre Processos de Negócio e de Software através de Gerência do Conhecimento
}

\author{
Cátia Galotta ${ }^{1,2}$, Káthia M. Oliveira ${ }^{3}$, Ana R. C. Rocha ${ }^{1}$ \\ ${ }^{1}$ COPPE-UFRJ, Caixa Postal 68511, CEP 21945970, Rio de Janeiro, Brazil \\ ${ }^{2} \mathrm{IPqM}$ - Instituto de Pesquisas da Marinha \\ ${ }^{3} \mathrm{UCB}$ - Universidade Católica de Brasília \\ cgalotta@centroin.com.br, kathia@ucb.br, darocha@cos.ufrj.br
}

\begin{abstract}
RESUMO
Para uma boa gestão da qualidade, é necessária a identificação de processos inter-relacionados e interativos, pois, freqüentemente, a saída de um processo resultará diretamente na entrada do processo seguinte. São importantes a identificação sistemática e a gestão dos processos empregados na organização e, particularmente, a identificação e gestão das interações entre tais processos. Este artigo aborda o apoio integrado aos processos de negócio e de software através da integração entre Ambientes de Desenvolvimento de Software, responsáveis pelo suporte ao processo de desenvolvimento de software, e Ambientes de Gerência de Conhecimento, responsáveis pelo suporte aos processos que não são de software, mas que interagem com aquele.
\end{abstract}

Palavras-chave: Processo de Negócio, Processo de Software, Gerência do Conhecimento

\begin{abstract}
For a good quality management, it is necessary the identification of interrelated and interactive processes. Frequently, the final artifact of a process will result directly in a required artifact of the following process. It is important to identify and systematically manage the organization's processes and, particularly, to identify and manage the interactions among such processes. This paper shows a proposal to integrate the business processes and the software process through the integration of a Software Development Environment, that is responsible for the support of the software development process, to a Knowledge Management Environment, that is responsible for the support of the non-software processes that interact with the software process.
\end{abstract}

Key words: Business Process, Software Process, Knowledge Management

\section{INTRODUÇÃO}

Tem-se observado, na literatura, uma grande preocupação com processos de software. Essa preocupação fica explícita nas discussões sobre o CMM [1], CMMI [2], na melhoria de processos e na norma NBR ISO 12207 [3]. No entanto, por mais irônico que pareça, entre as formas erradas de se iniciar a definição de um processo de software, a mais comum é escrever o processo [4]. Antes de começar a escrever, a equipe incumbida dessa missão precisa conversar com as pessoas que efetivamente trabalham com o desenvolvimento de produtos de software na organização, ouvir os relatos de problemas ocorridos durante a realização de suas atividades cotidianas e suas sugestões de solução. É fundamental, também, ter definido claramente as metas da organização e seus objetivos de negócio já que, normalmente, os processos de negócio da organização interagem com os processos de software. Só então é possível definir um processo de software que reflita as melhores práticas da organização e que tenha a adesão de seus funcionários.

A importância da interação entre os processos de software e os processos de negócio da organização fica clara quando as normas NBR ISO 9000 [5] e NBR ISO 9001 [6] abordam o 
fato de que para que as organizações funcionem de forma eficaz, elas têm que identificar processos inter-relacionados e interativos, pois, freqüentemente, a saída de um processo resultará diretamente na entrada do processo seguinte. Essas normas evidenciam a importância da identificação sistemática e da gestão dos processos empregados na organização e, particularmente, das interações entre tais processos. Para uma boa gestão da qualidade, é necessário apoio integrado a ambos. A maior vantagem dessa abordagem, segundo a norma NBR ISO 9001, é o controle contínuo que ela permite sobre a ligação entre os processos individuais dentro da organização bem como sua combinação e interação, enfatizando a necessidade de considerar os processos em termos de valor agregado.

Nossa proposta é apoiar de forma integrada os processos de negócio e de software através da integração de Ambientes de Desenvolvimento de Software (ADS) construídos a partir da infra-estrutura da Estação TABA [7], responsáveis pelo suporte ao desenvolvimento de software, aos Ambientes de Gerência de Conhecimento construídos a partir da infra-estrutura do CORE-KM [8], responsáveis pelo suporte aos processos que não são de software, mas que interagem com aquele.

Para detalhar este trabalho, descreveremos, na seção 2, o estágio atual dos ADS no contexto da Estação TABA. Apresentaremos, na seção 3, a definição e a construção do CORE-KM, um ambiente customizável para gerência de conhecimento. Na seção 4, descreveremos como o conhecimento adquirido ao longo dos processos organizacionais será utilizado para apoiar o desenvolvimento de software. Por fim, a quinta seção apresentará o estágio atual do nosso trabalho.

\section{AMBIENTES DE DESENVOLVIMENTO DE SOFTWARE NO CONTEXTO DA ESTAÇÃO TABA}

Com o objetivo de apoiar o desenvolvimento de software, foi proposto o uso de Ambientes de Desenvolvimento de Software (ADS), que são sistemas computacionais que provêm suporte para o desenvolvimento, reparo e melhorias em software e para o gerenciamento e controle dessas atividades [9]. Para isso, são compostos de um repositório, que armazena todas as informações relativas ao projeto de software, e de um conjunto de serviços e ferramentas, que apóiam as atividades técnicas e gerenciais a serem realizadas.

No início da década de noventa, foi definida e construída, no Programa de Engenharia de Software e Computação da COPPE, a Estação TABA que é um meta-ambiente capaz de gerar, através de instanciação, ambientes de desenvolvimento de software adequados às particularidades de processos de desenvolvimento e de projetos específicos. Na Estação TABA, um ADS é instanciado a partir da definição de um processo de desenvolvimento. Posteriormente foram realizadas importantes evoluções nos ambientes gerados. Uma das evoluções permite que a Estação TABA instancie Ambientes de Desenvolvimento de Software orientados à Organização (ADSOrg).

ADSOrg é definido como uma classe de ambientes de desenvolvimento de software que apóia a atividade de engenharia de software em uma organização, fornecendo o conhecimento acumulado pela organização e relevante para essa atividade, ao mesmo tempo em que apóia, a partir de projetos específicos, o aprendizado organizacional em engenharia de software [10]. Desse modo, um ADSOrg inclui conhecimento sobre, por exemplo, normas e diretrizes organizacionais, melhores práticas, relatos de experiências, entre outros. 
Com essa evolução, a Estação TABA passou a permitir também a configuração de ambientes para organizações específicas. O ambiente configurado contém o processo padrão e os processos especializados para os tipos de software desenvolvidos na organização. Esse ambiente irá armazenar e prover todo o conhecimento capturado pela organização e importante para o desenvolvimento e a manutenção de software. Um ambiente configurado TABA contém, ainda, ferramentas para a instanciação de processos e tem a capacidade de gerar ambientes de desenvolvimento de software para projetos específicos a partir dos processos instanciados (ADSOrg). Os ambientes instanciados são os ambientes que apóiam o desenvolvimento propriamente dito dos produtos de software. Esses ambientes têm acesso ao conhecimento armazenado no repositório da organização. A figura 1 mostra o esquema utilizado para configuração de ambientes configurados para organizações específicas a partir da Estação TABA e para a instanciação de ADSOrg para projetos específicos a partir dos ambientes configurados.

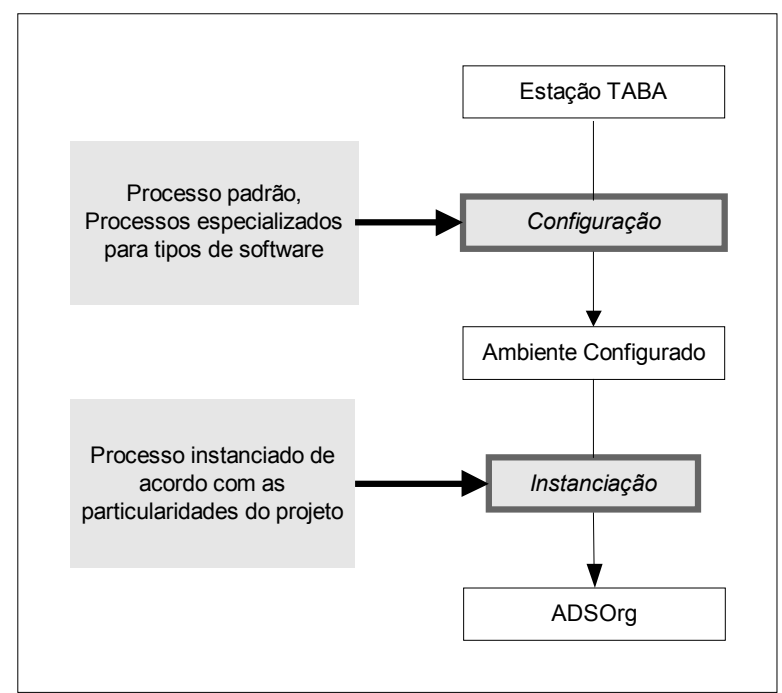

Figura 1 - Esquema para geração de ambientes a partir da Estação TABA [10].

A definição do processo padrão e a sua especialização de acordo com os tipos de software desenvolvidos na organização são realizadas na Estação TABA, como pré-requisito para a configuração do ADSOrg. Tanto a definição do processo padrão quanto a sua especialização são tarefas complexas, que exigem ampla experiência na definição de processos, além de profundo conhecimento da organização. Dessa forma, considerou-se conveniente que os ambientes fossem configurados já com esses processos definidos. Consultores na área de processo e profissionais experientes da organização trabalharão em conjunto na definição dos processos padrões e especializados, de forma a fornecer uma base confiável para a definição de processos para projetos específicos. A instanciação dos processos especializados é realizada no Ambiente Configurado, para que a organização tenha liberdade para definir os processos mais adequados às particularidades de cada um de seus projetos.

Uma experiência de configuração foi realizada para a Fundação Bahiana de Cardiologia, gerando o ambiente CORDIS-FBC [11]. Esse ADS contém conhecimento para apoiar atividades de desenvolvimento de software em cardiologia. Esse conhecimento engloba desde aspectos gerais como conhecimento sobre técnicas e métodos de desenvolvimento de software 
até aspectos específicos de uma organização, como conhecimento sobre diretrizes e melhores práticas organizacionais, além do conhecimento do domínio de cardiologia.

\section{CORE-KM: UM AMBIENTE CUSTOMIZÁVEL PARA GERÊNCIA DE CONHECIMENTO}

A Gerência de Conhecimento é definida de diferentes maneiras pelos especialistas. Parte da complexidade em se definir exatamente a Gerência de Conhecimento vem da dificuldade em se explicar o termo conhecimento. Muitos autores têm definido o conhecimento em função de dado e informação $[12,13]$, onde dado é um conjunto de fatos discretos e objetivos sobre eventos. O dado não diz nada sobre sua importância ou relevância, mas é o material básico para a criação da informação. A informação é uma mensagem com emissor e receptor, que tem a finalidade de mudar a forma como o receptor percebe algo, tem impacto no seu julgamento ou comportamento. Dado transforma-se em informação quando é adicionado significado. Já o conhecimento é a combinação de dados e informações a qual podem ser adicionadas opiniões, perfis e experiências para formar uma afirmativa que poder ser usada numa tomada de decisão.

Tradicionalmente, a gerência de conhecimento tem sido vista como o esforço em capturar, armazenar e disseminar o conhecimento [13], usando uma combinação de tecnologia da informação e processo de negócio. Em um Ambiente de Gerência de Conhecimento, o computador apóia o desenvolvimento das atividades ricas em conhecimento através da manipulação de informação, enquanto um repositório guarda o conhecimento criado e o dissemina através da organização.

O ambiente CORE-KM (Customizable Organizational Resources Environment with Knowledge Management) é um ambiente customizável para gerência de conhecimento em diferentes organizações, capaz de apoiar seus processos organizacionais. A idéia surgiu da constatação de que cada organização tem características próprias e processos organizacionais diversos que, portanto, devem ser apoiados por um ambiente de gerência de conhecimento específico. Cada customização constitui um ambiente diferenciado que contempla as características particulares de uma organização específica.

Para apoiar a definição, customização e execução de ambientes de gerência de conhecimento específicos, o ambiente CORE-KM possui as seguintes funcionalidades: (i) auxiliar o engenheiro de conhecimento na especificação do ambiente de gerência de conhecimento mais adequado à organização; (ii) auxiliar o engenheiro de conhecimento na customização do ambiente de gerência de conhecimento; (iii) permitir ao engenheiro de software a integração, ao ambiente customizado, de ferramentas desenvolvidas para apoiar processos específicos da organização; (iv) permitir às organizações a execução do ambiente customizado independentemente do ambiente CORE-KM.

Para satisfazer a essas funcionalidades, os seguintes requisitos foram identificados como requisitos gerais do ambiente CORE-KM: (i) ser customizável para diferentes organizações de forma a atender às especificidades da gerência de conhecimento de cada organização; (ii) possuir interface consistente que permita uma utilização consistente de seus recursos e ferramentas. As interfaces com o usuário também devem ser customizáveis para cada organização; (iii) possuir um modelo de armazenamento de dados comum possibilitando às ferramentas compartilhar e utilizar essas informações de forma natural e consistente; (iv) fornecer assistência inteligente ao usuário que facilite o uso do próprio ambiente e das 
ferramentas disponíveis.

Cada customização atende às especificidades da organização para a qual o ambiente está sendo customizado. Sendo assim, os requisitos dos ambientes customizados a partir do CORE-KM podem variar de acordo com o perfil e os objetivos da gerência de conhecimento na organização. No entanto, foi possível identificar um conjunto inicial de requisitos [14] que estará presente nos ambientes customizados. São eles:

(i) Coletar e organizar sistematicamente o conhecimento de diversas fontes: o conhecimento necessário à execução de um trabalho está normalmente distribuído em várias fontes como papel, documentos eletrônicos, desenhos e anotações dos indivíduos. A captura do conhecimento interno e externo à organização deve ser realizada de forma sistemática e estruturada ao longo da execução dos processos, convertendo conhecimento tácito em conhecimento explícito;

(ii) Ser capaz de construir novo conhecimento: o ambiente deve apoiar as atividades de pesquisa e desenvolvimento da organização utilizando para tal os processos organizacionais intensivos em conhecimento que já tenham sido identificados;

(iii) Preservar o conhecimento: a preservação do conhecimento deve ficar a cargo da Memória Organizacional que é o repositório de todo o conhecimento existente ou que poderá vir a existir na mesma. Sua finalidade é assegurar que o conhecimento desejado possa ser recuperado no tempo e no lugar certo [15];

(iv) Apresentar o conhecimento de forma passiva e ativa: a apresentação do conhecimento de forma passiva, onde o usuário busca pelo conhecimento, pode não ser suficiente. Isso ocorre devido à falta de tempo do usuário para pesquisar em meio a uma grande quantidade de conhecimento irrelevante à solução do problema. É necessário que a divulgação do conhecimento ocorra, também, de forma ativa, ou seja, divulgar o conhecimento relevante, de acordo com o perfil do usuário que está usando o ambiente, no momento adequado e no formato ideal para habilitar a ação correta, respeitando a necessidade do usuário;

(v) Ser capaz de valorar o conhecimento: é necessária a existência de métricas e outros mecanismos de avaliação, visando identificar que conhecimento é efetivo e está sendo utilizado e qual o valor desse conhecimento para os negócios da organização;

(vi) Explorar a realimentação do usuário para manter e evoluir o ambiente: o esforço de manutenção deve ser minimizado usando a realimentação do usuário para lidar com informações incompletas, incorretas ou constantemente variáveis. Dessa forma, permite-se a evolução da memória organizacional e o descarte de conhecimento não relevante ao negócio da empresa. A manutenção do conhecimento permite sua evolução e o descarte de conhecimento não relevante ao negócio da empresa;

(vii) Ser integrável aos sistemas de trabalho já existentes: para ter uma melhor aceitação, é necessário que o ambiente de gerência de conhecimento tenha interface direta com as ferramentas e sistemas que sejam usualmente utilizados na organização.

Para atender a esses requisitos, foi definida uma infra-estrutura com base em propostas encontradas na literatura $[14,16]$. A infra-estrutura é composta de um conjunto de atividades típicas de gerência de conhecimento, que representam as funcionalidades do ambiente 
customizado e se comunicam através de uma memória organizacional central. As atividades que compõem o ambiente implicam em uma interface, através de ferramentas, com as bases de conhecimento, formando uma rede de conhecimento baseada na Intranet da organização.

Considerando a definição de gerência de conhecimento como o processo completo de descoberta, aquisição, captura, criação, disseminação, utilização, filtragem, compartilhamento, aprendizado, manutenção, reutilização e renovação de todo o conhecimento tácito e explícito existente nas organizações [17], identificamos as seguintes atividades para fazer parte do ambiente customizado: aquisição, construção, disseminação, utilização, valoração e manutenção do conhecimento. A seguir detalharemos como a execução dessas atividades está sendo apoiada no ambiente customizado:

(i) Aquisição do Conhecimento: no ambiente customizado essa atividade é realizada segundo um processo de aquisição de conhecimento com atividades para levantar, filtrar e empacotar o conhecimento [18]. Foi definida e implementada uma ferramenta (ACKNOWLEDGE) para apoiar a execução desse processo. A ferramenta ACKNOWLEDGE permite a aquisição do conhecimento ao longo dos demais processos ou de forma independente aos mesmos. A inclusão de um novo conhecimento é feita após crítica de especialistas responsáveis por filtrar o conhecimento relevante à organização;

(ii) Disseminação do Conhecimento: a disseminação do conhecimento no ambiente customizado ocorre de forma passiva ao longo da execução dos processos organizacionais e está em fase de estudo a disseminação ativa do conhecimento através do uso de agentes;

(iii) Valoração do Conhecimento: no ambiente customizado essa atividade é realizada a partir de um repositório de métricas padronizado, fornecido com o ambiente mas passível de evolução de acordo com as necessidades da organização. Está em fase de definição uma ferramenta que será responsável pela atribuição (automática e/ou manual) de valor a alguns atributos do conhecimento como [19]: abstração, idade, disponibilidade, localização, clareza, significado, relevância e importância;

(iv) Manutenção do Conhecimento: no ambiente customizado, a manutenção será realizada a partir de uma metodologia para limpeza periódica da base de conhecimento com o descarte de conhecimento não relevante e não utilizado. A relevância e a utilização do conhecimento serão obtidas a partir da valoração do mesmo;

(v) Construção do Conhecimento: essa atividade estará presente apenas nos ambientes customizados para organizações que realizam atividades de pesquisa, onde os processos específicos devem ser identificados e modelados;

(vi) Utilização do Conhecimento: essa atividade estará presente em todos os ambientes customizados, mas, como está relacionado aos processos organizacionais e de negócio, irá variar de organização para organização. Da mesma forma como acontece na atividade de construção do conhecimento, os processos específicos devem ser identificados e modelados.

A preservação do conhecimento fica a cargo da memória organizacional que, no ambiente CORE-KM, é formada pelas bases de conhecimento. Cada ambiente customizado terá sua própria memória organizacional composta pelas bases selecionadas dentre as existentes no CORE-KM, além das bases pertencentes às ferramentas específicas desenvolvidas para a organização. Logo após a customização, as bases que compõem a memória organizacional 
estarão vazias e deverão ser populadas com conteúdo pertinente à organização. A memória organizacional dos ambientes customizados a partir do CORE-KM é composta por: (i) Base de Currículos, que contém currículos de pessoal interno e externo à empresa, de forma a se obter informações e localizar profissionais com determinado perfil, que atendam determinadas características ou necessidades; (ii) Base de Guidelines, que contém guidelines relacionadas à execução dos processos da organização; (iii) Ontologias, que são utilizadas com o objetivo de facilitar a comunicação entres os usuários da memória organizacional e as associações entre as múltiplas bases de conhecimento; (iv) Base de Conhecimento de Melhores Práticas, que contém descrições dos processos da empresa que aparentam ser a melhor forma de realizar as atividades; (v) Base de informações bibliográficas, que contém informações extraídas, por exemplo, de jornais recentes, normas, documentos, projetos, manuais, artigos publicados em revistas e conferências; (vi) Base de Conhecimento de Lições Aprendidas, que contém informações de experiências de sucesso e fracasso da organização; (vii) Base de Dados, contendo informações gerais sobre clientes, fornecedores e parceiros.

Além das atividades definidas para o ambiente customizado, o CORE-KM possui a atividade de Identificação do Conhecimento que tem como objetivo identificar a necessidade de conhecimento da organização a partir de visitas à mesma. Trata-se da primeira atividade da customização. Deve-se identificar o domínio onde a organização atua e as suas principais atividades, levantar requisitos de conhecimento da organização e identificar os objetivos do ambiente de gerência de conhecimento. A necessidade de conhecimento é identificada, basicamente, através de entrevistas e questionários. Nessa atividade também são identificados os processos organizacionais específicos, intensos em conhecimento. No CORE-KM, a identificação de conhecimento é um processo genérico, sendo uma atividade pertinente apenas ao ambiente customizável. A figura 2 apresenta, de forma esquemática, a infraestrutura do CORE-KM. Cada ambiente customizado tem um a infra-estrutura similar, retirando-se apenas a atividade de Identificação do conhecimento.

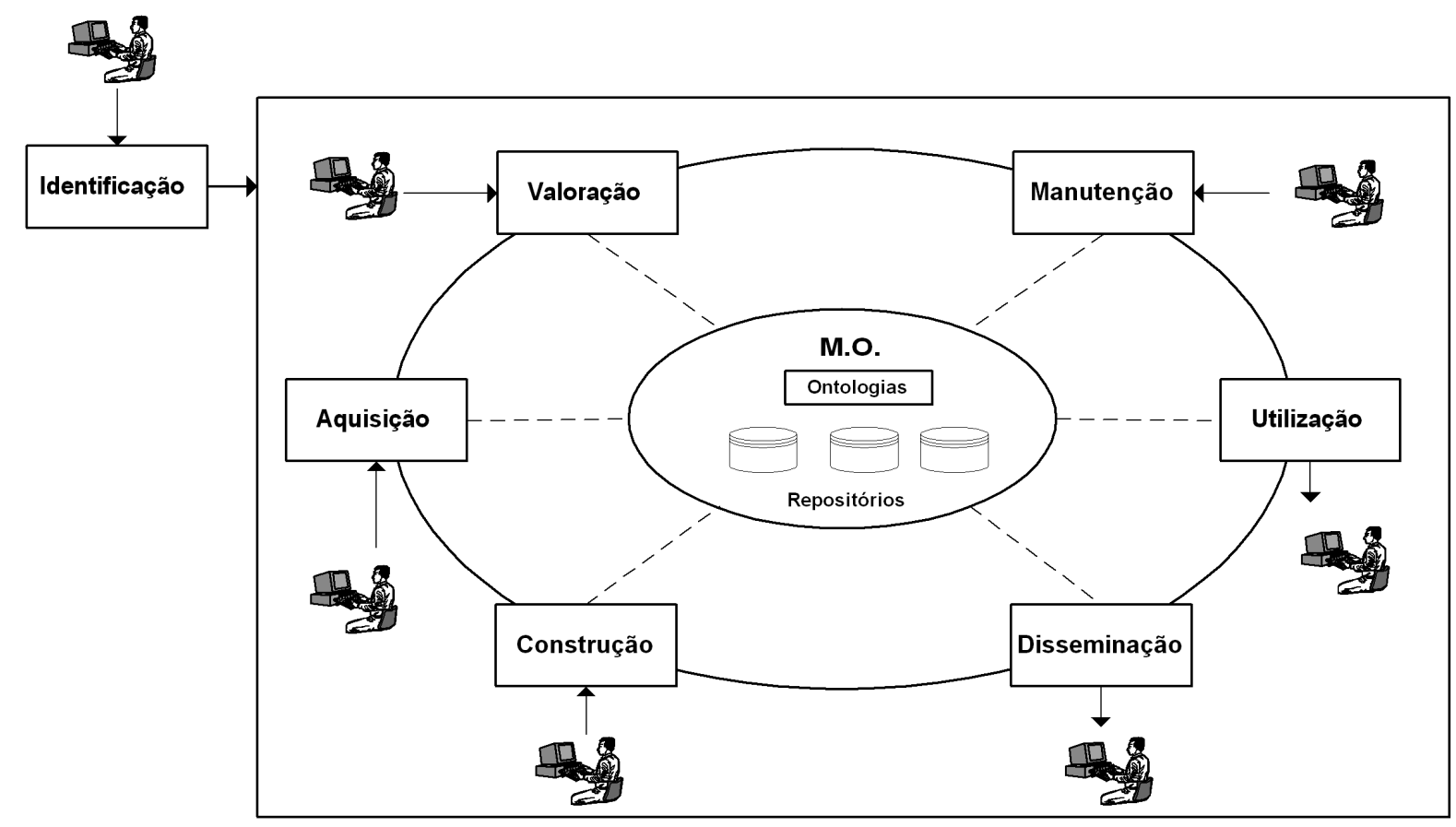

Figura 2 - Representação, de forma esquemática, da infra-estrutura do CORE-KM 


\section{CUSTOMIZAÇÃO DE AMBIENTES DE GERÊNCIA DE CONHECIMENTO}

A customização de um ambiente de gerência de conhecimento a partir do CORE-KM é realizada de acordo com um processo de customização cujo objetivo é descrever os procedimentos para a customização e seu produto final é um ambiente de gerência de conhecimento disponibilizado para implantação na organização. As atividades detalhadas a seguir constituem o Processo de Customização definido:

(i) Identificar a necessidade de conhecimento, que inclui subatividades para identificar o problema e definir o objetivo do ambiente de gerência de conhecimento customizado para a organização específica;

(ii) Estabelecer prioridades, que contém guidelines (diretrizes) relacionadas à execução dos processos da organização;

(iii) Elaborar proposta de fornecimento, que consiste em elaborar o plano do projeto e formalizar o contrato;

(iv) Realizar projeto criativo inicial, definindo as principais características e requisitos do ambiente;

(v) Realizar projeto de interface web, definindo os elementos que vão compor as páginas web;

(vi) Construir a versão inicial do ambiente customizado, escolhendo e customizando as ferramentas genéricas que farão parte do ambiente customizado;

(vii) Testar e avaliar a versão inicial;

(viii) Desenvolver ferramentas para processos específicos, de acordo com o processo de desenvolvimento de ferramentas;

(ix) Testar e avaliar o ambiente com as ferramentas integradas (versão final);

(x) Realizar implantação, que consiste em implantar o ambiente customizado em seu local de uso.

As primeiras sete atividades do Processo de Customização são realizadas seqüencialmente. No entanto, a oitava atividade (Desenvolver Ferramentas para Processos Específicos) é realizada de acordo com um Processo de Desenvolvimento de Ferramentas para Processos Específicos de forma a garantir uniformidade no desenvolvimento das ferramentas. As atividades desse processo podem ter início logo após a atividade de Testar e Avaliar a Versão Inicial ou podem ter início em qualquer tempo após a conclusão da atividade de Elaborar a Proposta de Fornecimento. Essa decisão fica a critério do Gerente do Projeto, pois, nesse momento, o Engenheiro do Conhecimento já identificou quais ferramentas serão construídas. A figura 3 apresenta os dois processos modelados segundo notação definida por [20].

Com a infra-estrutura e os processos de customização e de desenvolvimento de ferramentas definidas, selecionamos a tecnologia de representação para que a implementação pudesse ser iniciada. Estamos utilizando uma arquitetura em quatro camadas composta por: Camada cliente: compreende o programa de visualização da aplicação através de uma rede Internet ou Intranet. O programa de visualização utilizado é o Microsoft Internet Explorer; Camada de apresentação: compreende o conjunto de páginas para gerar conteúdo para a camada cliente. Essa camada foi implementada utilizando a linguagem HTML e C\#. O servidor da camada de apresentação é o Microsoft Internet Information Server e o framework 
ASP.NET; Camada da lógica da aplicação: compreende as regras do negócio, as quais determinam de que maneira os dados serão utilizados. Essa camada foi implementada utilizando a linguagem de programação C\# utilizando o paradigma de orientação a objetos e Camada de dados: compreende a base de armazenamento de dados e os procedimentos de manipulação desses dados. O servidor da camada de dados é o Microsoft SQL Server e os procedimentos de manipulação de dados foram implementados utilizando o mecanismo de stored procedures.

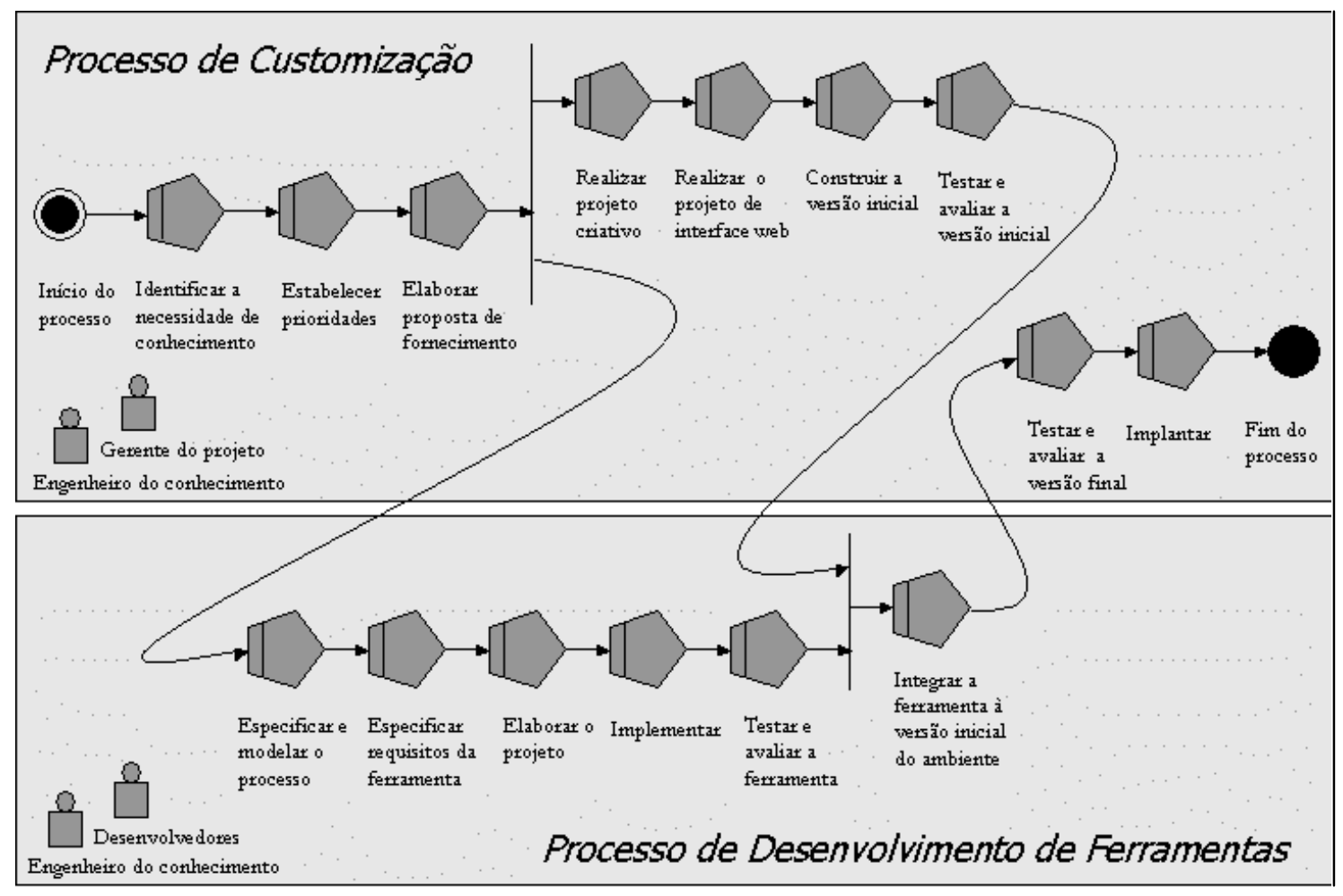

Figura 3 - Processo de Customização e Processo de Desenvolvimento de Ferramentas

A necessidade de implementação de um conjunto de serviços que atenda às funcionalidades de auxiliar o engenheiro do conhecimento na especificação e na customização do ambiente de gerência de conhecimento levou à construção de uma ferramenta para apoiar a execução do Processo de Customização (CORE-KM Customizer). A figura 4 mostra a página de abertura do ambiente CORE-KM. O link "Customizar Ambiente de Gerência de Conhecimento" direciona o usuário para a ferramenta CORE-KM Customizer fornecendo apoio ao usuário durante todo o processo de customização do ambiente. O link "Administração do Ambiente" direciona o administrador do ambiente a uma área reservada (figura 5) onde é possível realizar diversas operações como cadastro de usuários e senhas, cadastro de processos específicos e manutenção de listas. A figura apresenta uma página referente ao link "Administração do Ambiente" onde é possível cadastrar e recuperar atividades de processos específicos definidos. A ferramenta permite a recuperação, a qualquer tempo, de todo esse conhecimento que está preservado na memória organizacional do COREKM.

A figura 6 apresenta uma página da ferramenta CORE-KM Customizer que se refere ao apoio à atividade da gerência de conhecimento Identificação do Conhecimento. A ferramenta permite o cadastro e recuperação de informações gerais sobre a organização (como endereço, 
área de atuação, número de funcionários e distribuição geográfica), entrevistas realizadas e questionários aplicados. De posse dessas informações, o Engenheiro de Conhecimento identifica os problemas existentes na organização e que possam ser solucionados através da implantação de um ambiente de gerência de conhecimento. O Engenheiro do Conhecimento identifica, também, se existe algum sistema de informação ou algum banco de dados na organização que se deseje integrar ao ambiente customizado. Finalmente, o Engenheiro do Conhecimento estabelece os objetivos do ambiente customizado, colocando em ordem de prioridade os processos que serão apoiados pelo ambiente customizado e sugere alternativas de solução. A interface obriga o usuário a seguir o workflow do processo de customização representado pelos botões sempre presentes à esquerda da tela. A ferramenta disponibiliza, também, dois botões à direita, ao lado do título da atividade que está sendo realizada. O botão com o símbolo de um livro disponibiliza o conhecimento necessário à realização da tarefa e o botão com o símbolo de uma lâmpada aceita que o usuário dê sugestões de melhorias na execução da atividade.

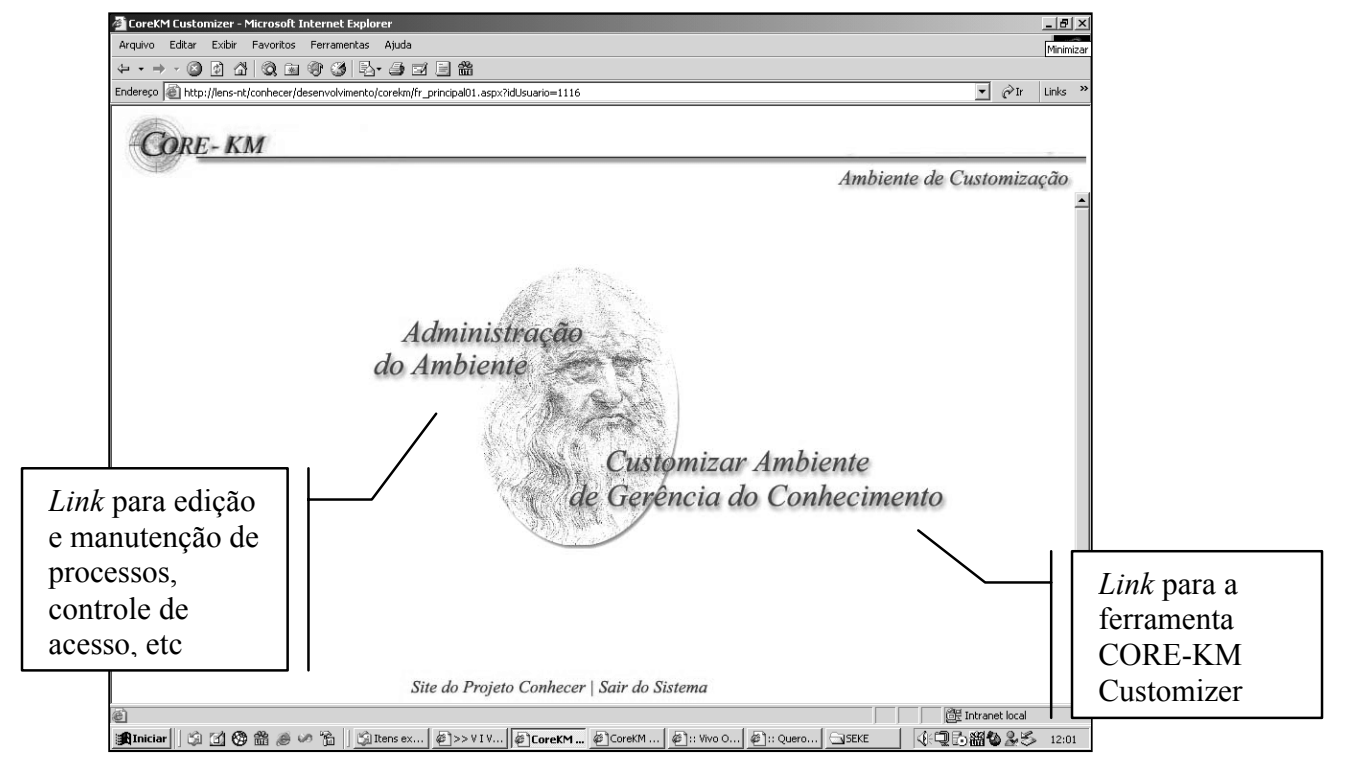

Figura 4 - Página de principal do CORE-KM

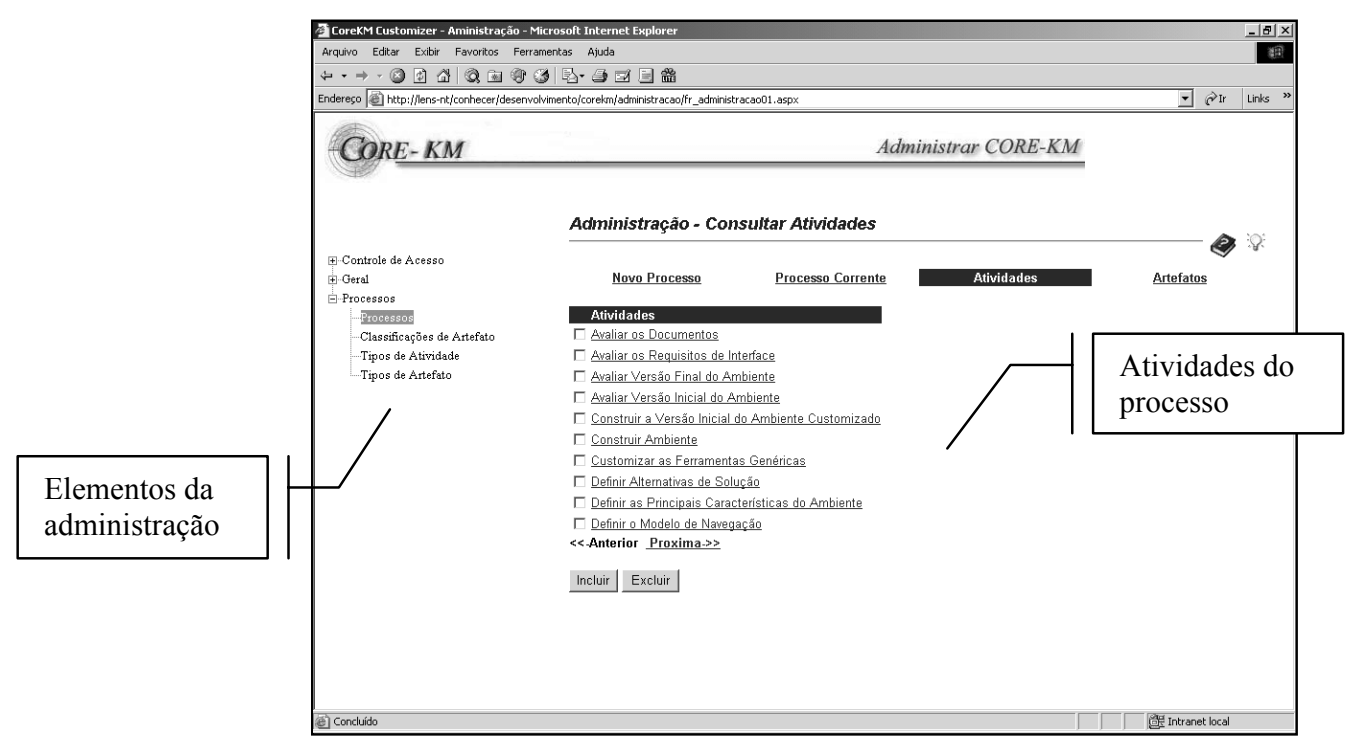

Figura 5 - Página da administração do CORE-KM 


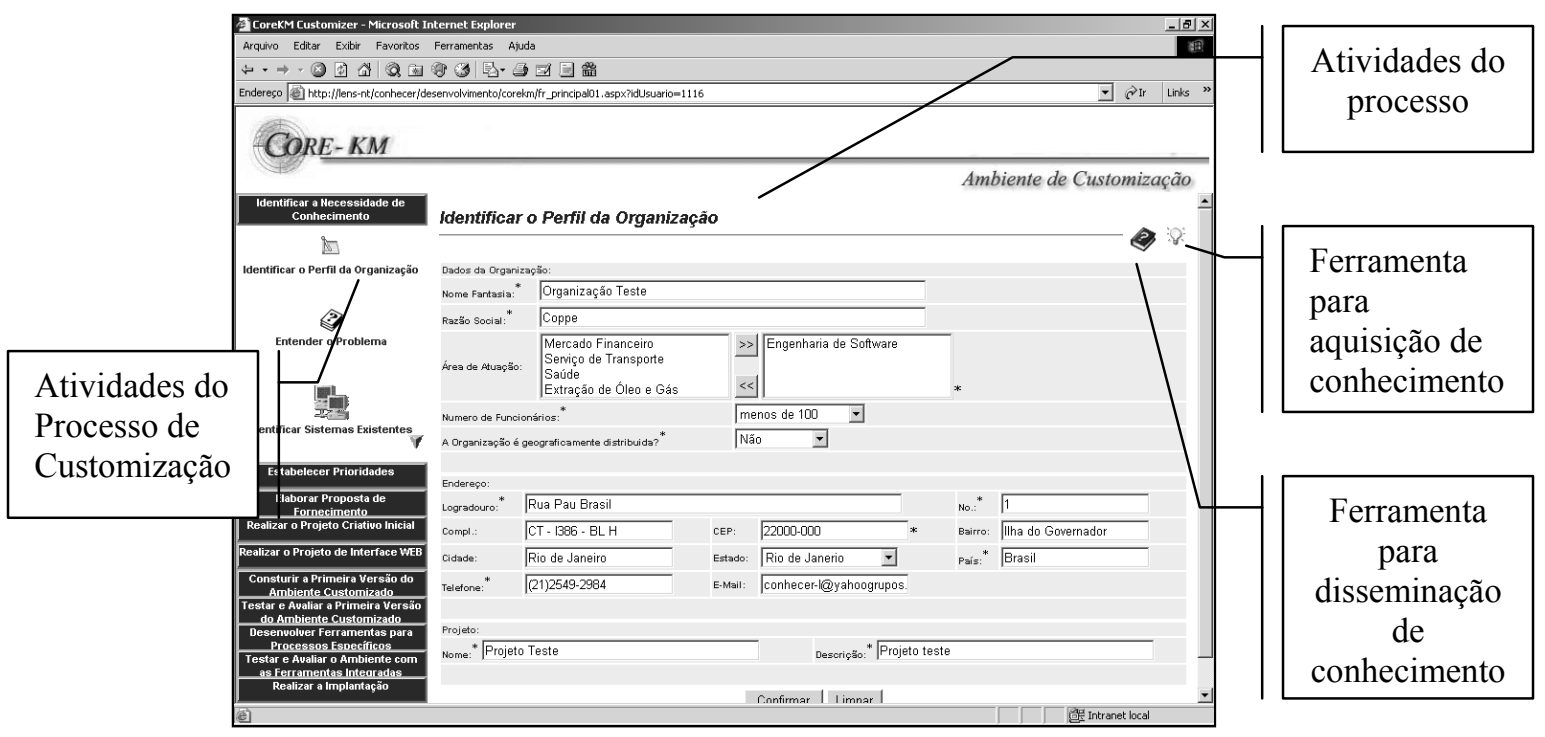

Figura 6 - Página da ferramenta CORE-KM Customizer

\section{APOIO INTEGRADO AOS PROCESSOS DE NEGÓCIO E AOS PROCESSOS DE SOFTWARE}

O desenvolvimento de software é um tipo de negócio cujas atividades são intensivas em conhecimento e envolvem várias pessoas trabalhando ao mesmo tempo em diferentes fases. Em organizações que trabalham com pesquisa e desenvolvimento (P\&D), por exemplo, é comum a necessidade de transferência de conhecimento entre os grupos de trabalho de maneira rápida e eficiente, principalmente entre o grupo de pesquisadores e o grupo de desenvolvedores de software. Em geral, nessas organizações, o processo de pesquisa e o processo de software ocorrem de forma simultânea, sendo que os artefatos produzidos em um processo são requeridos no outro. É normal ocorrer esse tipo de interação entre o processo de software e os processos que não são de software, mas que mantém interface com aquele, evidenciando a necessidade de um apoio integrado.

Nossa proposta de solução para esse problema é desenvolver mecanismos que permitam integrar um Ambiente Configurado pela Estação TABA a um ambiente de gerência de conhecimento customizado a partir do CORE-KM. A integração que estamos propondo será realizada na atividade de Utilização do Conhecimento (figura 7). Essa solução parece ser interessante para qualquer organização onde o desenvolvimento de software tenha interação com outros processos organizacionais, pois o desenvolvedor de software trabalhando no Ambiente Configurado TABA, terá acesso ao conhecimento adquirido e disponibilizado ao longo dos processos organizacionais. Os mecanismos para realização da integração estão em fase de estudo e prototipação. 


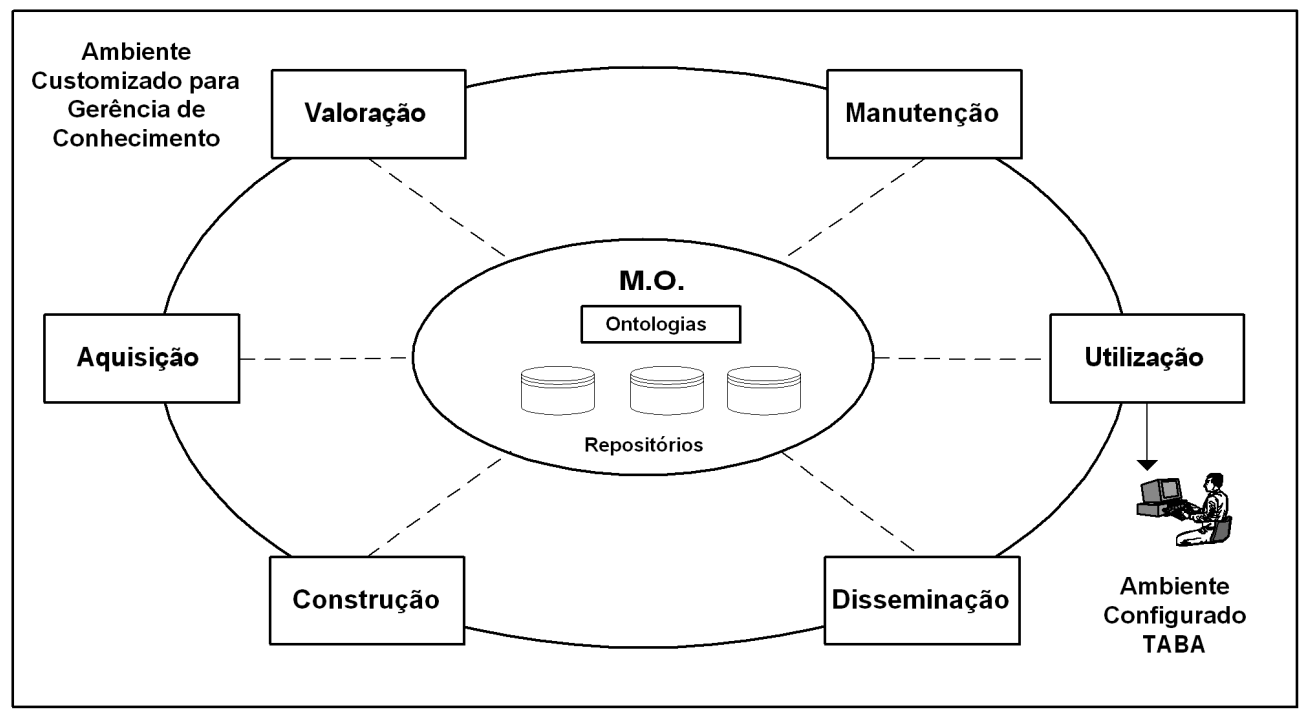

Figura 7 - Integração entre um Ambiente Customizado a partir do CORE-KM e um Ambiente Configurado TABA

\section{ESTÁGIO ATUAL E TRABALHOS FUTUROS}

Dois experimentos de customização foram realizados a partir do processo de customização definido e do uso da ferramenta CORE-KM Customizer. A primeira experiência, o ambiente CardioKnowledge [21], foi realizada para a Fundação Bahiana de Cardiologia. A segunda experiência de customização foi realizada para uma empresa de desenvolvimento de software, a Tecteam [22], produzindo o ambiente TecKnowledge.

Já foram realizados, também, dois experimentos com o processo de desenvolvimento de ferramentas específicas. Uma das ferramentas é a CardioResearch [21] que apóia os processos da Fundação Bahiana de Cardiologia relacionados à pesquisa, parte do ambiente CardioKnowledge. Essa ferramenta disponibiliza para médicos cardiologistas, estudantes de graduação, corpo de enfermagem, residentes em cardiologia e pessoal de apoio administrativo, o conhecimento organizacional sobre os procedimentos para pesquisa em ambulatórios assistenciais e participação em estudos multicêntricos internacionais. A outra ferramenta é a Software Supply Manager [22] que apóia o processo de fornecimento de software no ambiente TecKnowledge. Essa ferramenta disponibiliza para o gerente do projeto o conhecimento organizacional sobre propostas, contratos e projetos, sugerindo conhecimento adquirido em projetos similares para apoiar novas estimativas de cronograma, custos, recursos, pessoal e qualidade do projeto. Para o desenvolvimento dessa ferramenta, o processo de fornecimento de software foi definido e modelado em conjunto com a empresa Tecteam e engloba todas as atividades relativas ao fornecimento como, por exemplo, a preparação da proposta comercial, a definição, execução e controle do plano do projeto, entre outras. As figuras 8 e 9 apresentam páginas dos dois ambientes customizados. 


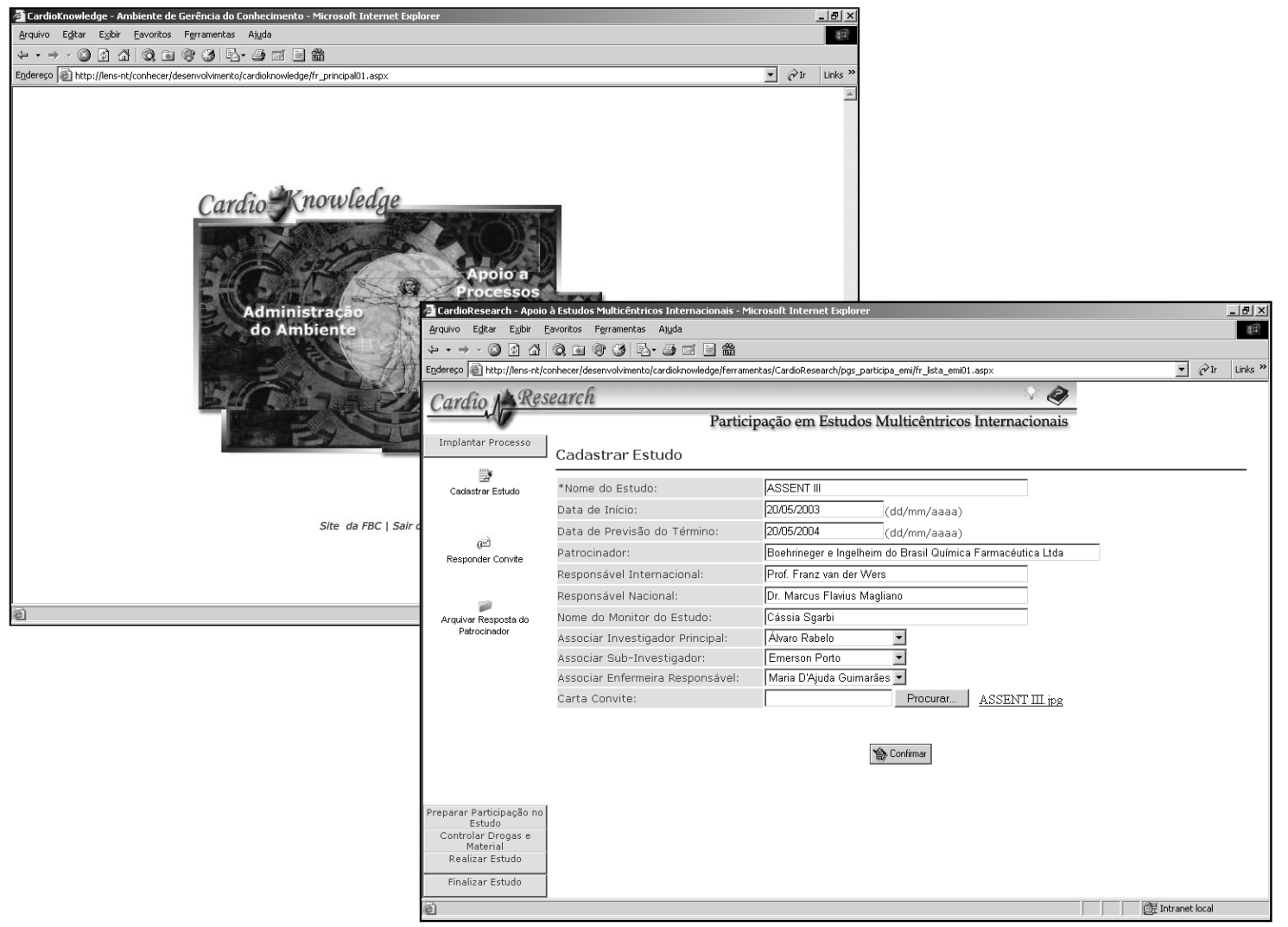

Figura 8 - Páginas do CardioKnowledge e do CardioResearch

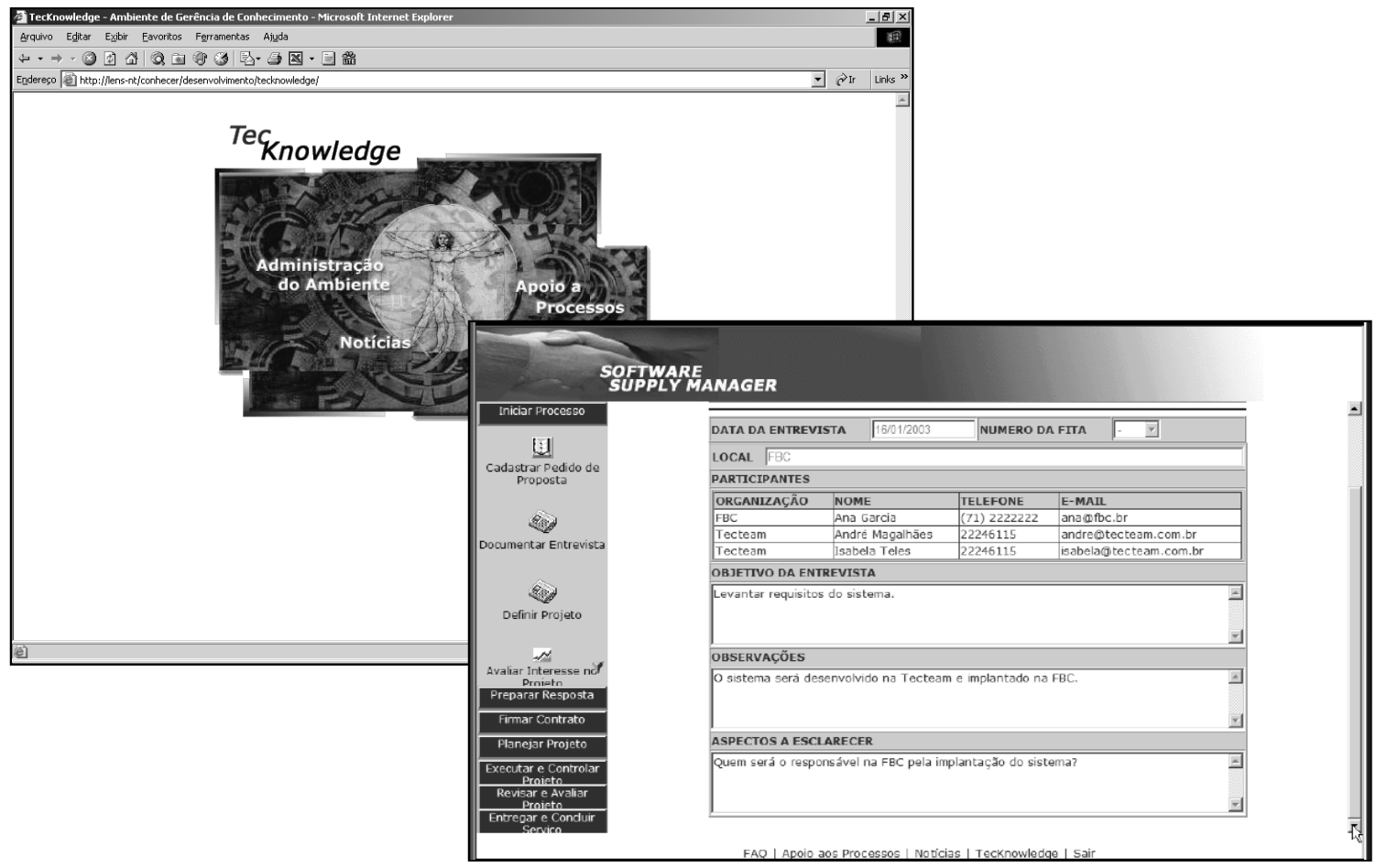

Figura 9 - Páginas do TecKnowledge e do Software Supply Manager 
Outras duas experiências de customização estão em curso. A primeira experiência está sendo realizada para a Gerência de Orçamentação e Contratação da área de Refino de uma empresa brasileira que trabalha na área de extração e refino de petróleo. A gerência é responsável pela realização de estimativas de custo, elaboração de orçamentos e pelo controle da execução de projetos de engenharia em refinarias brasileiras. Nesse contexto, o objetivo do ambiente de gerência de conhecimento customizado é apoiar a gestão de custos. Para atingir esse objetivo, o ambiente englobará além das ferramentas genéricas para aquisição, preservação e disseminação do conhecimento, ferramentas específicas para apoiar o processo de gestão de custos e o aprendizado organizacional nesse processo, mantendo dados de previsões e realizações anteriores. Para esse ambiente, já foram identificamos seus objetivos, necessidades específicas de conhecimento e realizados os projetos criativo inicial e de interface web. Os processos de estimativa, orçamentação, controle de custos e treinamento foram definidos e modelados. No momento, as ferramentas específicas estão sendo implementadas e em um futuro próximo serão integradas ao ambiente customizado.

A segunda experiência em curso é a customização de um ambiente de gerência de conhecimento que tem como objetivo apoiar a pesquisa e o desenvolvimento de software no Grupo de Sonar (GS) do Instituto de Pesquisas da Marinha (IPqM). O GS/IPqM é uma organização militar que desenvolve software para sonares de navios da esquadra brasileira a partir de pesquisas na área de acústica submarina. Como a cultura militar impõe uma alta rotatividade de pessoal, tanto a criação de novo conhecimento relativo ao domínio (acústica submarina) quanto a aquisição de conhecimento necessário ao desenvolvimento de software necessitam ser apoiados por um ambiente de gerência de conhecimento. Acreditamos que esse ambiente possibilitará a preservação do conhecimento criado pelos pesquisadores e sua rápida transformação em produtos de software. Para esse ambiente, identificamos seus objetivos, necessidades específicas de conhecimento e realizamos o projeto criativo inicial e de interface web. Está em curso a definição e a modelagem do Processo de Pesquisa da organização para que possamos criar uma ferramenta capaz de apoiar as atividades do processo que sejam passíveis de automação. Um ambiente de desenvolvimento de software foi construído a partir da Estação TABA para esse mesmo grupo em 2000 e, no momento, está sendo estendido de forma a se tornar um ambiente configurado TABA. Com esses dois ambientes construídos será possível realizar uma experiência de integração.

\section{AGRADECIMENTOS}

Os autores gostariam de agradecer a Mariano Montoni, Mariella Montoni e Viviane Costa pelo muito que colaboraram para a realização desse trabalho. Os autores agradecem ao CNPq pelo apoio financeiro ao projeto Ambientes de Desenvolvimento do Software Orientado a Organização.

\section{REFERÊNCIAS:}

[1] PAULK, M. C., WEBER, C. V., CURTIS, B. et al., 1995, The Capability Maturity Model: Guidelines for Improving the Software Process, Carnegie Mellon University, Software Engineering Institute, Addison-Wesley Longman Inc.

[2] CHRISSIS, M.B., 2003, KONRAD, M., SHRUM, S., CMMI: Guidelines for Process Integration and Improvement, Addison-Wesley.

[3] NBR ISO 12207, 1998, Tecnologia de Informação - Processos de Ciclo de Vida de Software, Associação Brasileira de Normas Técnicas, Rio de Janeiro, Brasil 
[4] RUS, I., LINDVALL, M., 2002, "Knowledge Management in Software Engineering", IEEE Software, vol 19, n. 3, pp. 26-38.

[5] NBR ISO 9000, 2000, Sistema de Gestão da Qualidade - Fundamentos e Vocabulário, Associação Brasileira de Normas Técnicas, Rio de Janeiro, Brasil

[6] NBR ISO 9001, 2000, Sistema de Gestão da Qualidade - Requisitos, Associação Brasileira de Normas Técnicas, Rio de Janeiro, Brasil

[7] ROCHA, A. R., AGUIAR, T. C., SOUZA, J. M., 1990, "Taba: A Heuristic Workstation for Software development", In: Proceedings of COMPEURO 90, Tel Aviv, Israel, May

[8] GAlOtTA, C., ROCHA, A. R. C., OliVEIRA, K. et al, 2003, "CORE-KM: Um Ambiente Customizável para Gerência de Conhecimento", In: I Workshop de Tecnologia da Informação e Gerência de Conhecimento, Fortaleza, Brasil, set

[9] MOURA, L. M. V., ROCHA, A. R. C., 1992, Ambientes de Desenvolvimento de Software, Publicações Técnicas COPPE/UFRJ, ES-271/92, Rio de Janeiro, Brasil.

[10] VIllELA, K., TRAVASSOS, G.H., ROCHA, A.R., 2001, "Ambientes de Desenvolvimento de Software Orientados à Organização", In: Proceedings of IDEAS'2001, San Jose, Costa Rica, Apr

[11] VILlELA, K., SANTOS, G., OLIVEIRA, K., et al., 2003, "Cordis-FBC: An Enterprise-Oriented Software Development Environment", LSO'2003, Abril, Suíça.

[12] NONAKA, I., TAKEGUCHI, H., 1995, The Knowledge-Creation Company: How Japanese Companies Create the Dynamics of Innovation, Oxford University Press, New York.

[13] FISCHER, G., OSTWALD, J., 2001, "Knowledge Management: Problems, Promises, Realities and Challenges", IEEE Intelligent Systems, Jan./Feb., pp. 60-72

[14] ABECKER. A., BERNARDI, A., HINKELMANN, K., et al., 1998, "Toward a Technology for Organizational Memories", IEEE Intelligent Systems, vol 13, n. 3, pp. 30-34, May/Jun

[15] KOUWENHOVEN, T., 1998, "Reengineering for Learning", SIGGROUP Bulletin, v.19, n.1 (Apr), pp. 19-45.

[16] PROBST. G., RAUB, S., ROMHARDT, K, 2000, Managing Knowledge: Building Blocks for Success, 1 ed., New York, John Wiley \& Sons

[17] O'LEARY, D.E., "Enterprise Knowledge Management", IEEE Computer, 1999, Mar, pp. 54-61.

[18] MONTONI, M., ROCHA, A. R., TRAVASSOS, G. H., 2003, "Aquisição de Conhecimento no Desenvolvimento de Software", $3^{\text {a }}$ Jornada Ibero-Americana de Engenharia de Software e Engenharia de Conhecimento, Valdivia, Chile, Novembro

[19] HOLPSAPPLE, C.W., 2003, "Knowledge and Its Attributes", Handbook on Knowledge Management, Springer, pp. 165-188.

[20] BONFIM, C.S., 2001, "Uma Ferramenta de Modelagem de Processos para Ambientes de Desenvolvimento de Software Orientados à Organização", Monografia de Final de Curso, Curso de Ciência da Computação da Universidade Federal da Bahia, Set.

[21] MONTONI, M. A., 2003, CardioKnowledge: Ambiente de Gerência de Conhecimento para Cardiologia, Tese de M. Sc., COPPE/UFRJ, Rio de Janeiro, RJ, Brasil

[22] COSTA, V., ROCHA, A.R., 2003, "Software Supply Manager: Uma Ferramenta de Apoio no Processo de Fornecimento de Software", In: I WGC, Fortaleza, Brasil, set. 